\title{
Case Study of Cross-cultural Adaptation and International Talents Training Model for Preparatory Overseas Students in China
}

\author{
Wang Yue \\ College of Humanities \& Sciences of Northeast Normal University \\ Changchun, China
}

\begin{abstract}
With the "One Belt One Road" initiative, the number of international students coming to China has increased year by year. The training of preparatory overseas students in countries along the "One Belt and One Road" initiative has become an important part of international talent training. This article takes the case of preparatory overseas students' cultural adaptation of the China Scholarship Council preparatory education base as the research object. According to the related theories of cross-cultural communication and cross-cultural social psychology, the cross-cultural adaptation of preparatory overseas students is analyzed. The cross-cultural adaptation of preparatory students can be analyzed from two angles of group and individual angles. Their cross-cultural adaptation staging and cross-cultural adaptation strategies all show special features. We should reflect on teaching and innovative teaching models, and provide experience and lessons for preparatory overseas students in international talent training.
\end{abstract}

Keywords-preparatory overseas student; cross-cultural adaptation; case study research; International talent training

\section{INTRODUCTION}

According to data derived from the Ministry of Education of the People's Republic of China, countries along the Belt and Road have become the main source of international students in China. In 2016, a total of 207,700 international students along the route came to China, with an increase of $13.6 \%$ on a yearon-year basis [1]. International pre-university students studying in China (hereinafter referred to as "pre-university students") are one of the main forces, and the number of them is significantly increasing. In order to guarantee the education quality for international undergraduate students who have received scholarships from the Chinese government, the State has established several pre-university education bases at some universities of China (such as Beijing Language and Culture University, Northeast Normal University, Central China Normal University, etc.). Each international student who comes to China for undergraduate or postgraduate education must first receive one year of basic Chinese and professional Chinese training at an pre-university education base. They may proceed

This Study is supported by the "13th Five-Year" Social Science Program 2017 of the Department of Education of Jilin Province (JJKH20170986SK), "Research on the Cultural Adaptation Cases of Pre-university Students in China Supported by the China Scholarship Council", and organized by WANG Yue. to the undergraduate program or master's degree program after passing the Chinese Proficiency Test (HSK Level 4) and the assessment by the China Scholarship Council (CSC).

As there are a large number of pre-university students from five continents, their lifestyles, spiritual value judgments and even group personalities differ, depending on county, region and national culture. Thus, one year of pre-university study is not only a process of learning a strange language, but also a challenge - adapting to the challenges from Chinese culture. From a personal point of view, the cross-cultural adaptation of an individual international pre-university student determines his/her learning attitude, motivation, method, interpersonal relationship and even the change in his/her values. From a group perspective, the cross-cultural adaptation of preuniversity students determines whether this group can serve as a bridge of economic, scientific, and cultural communication between China and the rest of the world and whether it can facilitate the great blueprint of international talent training proposed by the "Belt and Road" Initiative? Based on the above reasons, this paper studies the cross-cultural adaptation of pre-university students with cases as data and reviews the characteristics of such cross-cultural adaptation from the perspectives of intercultural communication and cross-cultural social psychology. It tries to analyze the effectiveness of the cross-cultural teaching methods adopted at pre-university education bases amidst dynamic changes of pre-university students' values, cross-cultural communication forms and abilities as well as cultural adaptation strategies. Also, constructive teaching concepts and measures are proposed to further explore the significance and inspiration of Chinese language teaching for international students in China and international talent training under the new situation.

\section{CASE STUDY}

This study lasted for five years and experienced a long-term accumulation process, with more than 300 people involved. The combination of diversified evidence sources, multiple-case study and single-case study was tried to be used. We pay attention to the validity and reliability of our study, try to combine case study, investigation and comprehensive analysis methods and other methods of study, striving to make this study a combination of qualitative and quantitative research methods. There has been no case tracking study on cross- 
cultural adaptation of a large number of pre-university students in China. I hope this study could be a useful attempt to provide some experience for pre-university education.

\section{A. Objects of Case Study}

The case study is designed for the pre-university students 2013-2017 from the Pre-university Department for International Students of Northeast Normal University, a preuniversity education base of the China Scholarship Council. According to the cases investigated, all cases involve 375 preuniversity students from 40 countries on five continents, accounting for $52.1 \%$ of all students (743) trained at the preuniversity education case for five years. The study objects are mainly African pre-university students, $78.2 \%$ of all international students relating to the cases. There are more men than women, and men account for $70 \%$ of all pre-university students involved. The average age of the study objects subjects are between 18 and 22 years old and the average duration of their stay in China is 5 months. They are basically at the same level in terms of Chinese proficiency. More than $81 \%$ of the pre-university students are Chinese beginners. Less than $20 \%$ of East Asian pre-university students have a certain Chinese foundation (equivalent to HSK2-3), and more than $86 \%$ of all pre-university students have come to China for the first time. (See Table I).

TABLE I. BASIC INFORMATION SHEET FOR INTERNATIONAL STUDENTS IN CHINA

\begin{tabular}{|c|c|c|c|c|c|c|c|}
\hline $\begin{array}{c}\text { Total of pre- } \\
\text { university } \\
\text { students } \\
\text { concerned }\end{array}$ & Male & Female & $\begin{array}{c}\text { Avera } \\
\text { ge age }\end{array}$ & $\begin{array}{c}\text { Share of } \\
\text { African pre- } \\
\text { university } \\
\text { students }\end{array}$ & $\begin{array}{l}\text { Share of Asian, } \\
\text { African } \\
\text { Oceanian } \\
\text { university } \\
\text { students }\end{array}$ & $\begin{array}{c}\text { Share of pre- } \\
\text { university } \\
\text { students as } \\
\text { Chinese } \\
\text { beginners }\end{array}$ & $\begin{array}{c}\text { Share of pre- } \\
\text { university } \\
\text { students as first } \\
\text { comers to China }\end{array}$ \\
\hline 375 & $70 \%$ & $30 \%$ & 20 & $78.2 \%$ & $21.8 \%$ & $81 \%$ & $86 \%$ \\
\hline
\end{tabular}

\section{B. Methodology}

The cases explored in this paper were written by Chinese teachers and undergraduates of the specialty of Teaching Chinese to Speakers of Other Languages. They have received professional training on Chinese teaching methods and crosscultural communication. The researchers conducted can indepth contact with the pre-university students. And the research was mainly collected by qualitative research methods, such as interview, observation, and collection of physical objects.

During the study of pre-university students in China for the first 10 months after they reached China (from September of the first year to June of the next year), the researchers and the pre-university students conducted an average of 2 to 3 interviews per week. Constrained by the pre-university students' Chinese proficiency, the first two months of interviews mainly adopted the form of open interview to understand "their ideas of important issues, perspectives on the problems, their interpretation of meanings, the concepts they used and how the concepts were expressed in their study and life", [2] aiming to help them in cross-cultural adaptation and reduce their emotion of resistance. Starting from the third month onwards, the semi-open interview was prioritized and the closed interview was regarded as a supplement. Questions about their study and life issues in cross-cultural adaptation were asked.

The main questions asked in the interviews were: 1 . the overseas study and cross-cultural training of pre-university students. 2. What makes you feel uncomfortable and satisfactory when they live in China? 3. What about your interpersonal relationship in China? What Chinese people do you interact with? What groups do you often interact with? 4. The main purpose of your coming to China to study Chinese, your learning direction and purpose at Chinese universities upon the completion of the pre-university courses. 5. Have you adapted to the teaching environment and methods in China? 6. What are the methods of Chinese language acquisition for pre- university students? And so on. The questions mainly focus on cross-cultural influence factors, interpersonal communication, and Chinese language acquisition. The purpose is to explore the reasons behind the cross-cultural adaptation of preuniversity students and to find a more reasonable teaching and management model.

Observation is also the main means of this study. The researchers are also single-class teachers or language partners of pre-university students. Therefore, they often carried out various learning or cultural activities together with preuniversity students, "listened and observed what they said and did in their mutual contact and direct experience with these students.” [2] Participatory observation and non-participatory observations ran throughout the entire study process, complementing the interviews. Researchers can clearly record the behavioral characteristics of the pre-university students at different times and in different spaces, and study the changes in such characteristics.

\section{Case Types}

The cases can be divided into two types according to the content of records: 1. Dynamic cross-cultural adaptation tracking cases. In this type of cases, one or two investigators track and observe a pre-university student and record in the form of long comprehensive cases the cross-cultural adaptation performance of the pre-university students in the Chinese language learning and living process in China for the previous year after they arrive in China. 2. Cross-cultural adaptation cases of individual events. Record the cross-cultural response and response method of a pre-university student, several preuniversity students, or all pre-university students in the same class in an event.

The cases can be divided into four types based on theme: 1 . Performance and changes of pre-university students' values in cultural adaptation. The case records the value orientation of pre-university students such as collectivism, individualism, 
universalism, specialism and distance of power, and dynamically records the changes in these values. 2. The performance of pre-university students in various stages of cross-cultural adaptation and the cultural adaptation strategies used in each stage. 3. Specific forms and communication styles of cross-cultural communication between pre-university students and Chinese. Case tracking records the use of mother tongues, inter-languages or target languages, and non-verbal communication. 4. Cross-cultural adaptation in a pre-university education environment, such as the response of pre-university students in the collision between Chinese and foreign education methods, teacher-student relationship, classroom communication, learning motivation, cognitive style, acquisition strategy and so on.

\section{INTERCULTURAL ADAPTATION PROCESS OF INTERNATIONAL PRE-UNIVERSITY STUDENTS}

"Cross-cultural adaptation refers to a process in which a group or an individual changes itself in order to adapt to the social environment.” [3] Pre-university students are a special group. They come from different countries and face a brand new Chinese social environment. However, as far as an individual is concerned, it is necessary to for him/her to get involved in cross-cultural communication with many other international pre-university students in his/her daily communication. Therefore, in the learning and living environment at the pre-university education base, it must face the shock of multiple cultures and experience the complex cross-cultural adaptation process.

Western scholars have proposed several cross-cultural adaptation staging theories based on their researches. The 4stage cross-cultural adaptation theory proposed by Oberg and Smalley is widely accepted. The first stage is the honeymoon stage, during which a positively optimistic attitude is shown towards the new culture of engagement. The second phase is the hostile stage, during which a hostile attitude towards the host culture is held due to the gap between reality and expectations. Cultural shock is prone to occur in this stage, i.e. "the anxiety generated by the people when losing the symbols of familiar social interactions in the new cultural context”. [4] The third stage is the recovery stage. Due to the improvement of the knowledge and skills of an individual in the host country, his/her ability to adapt to the new cultural environment will be improved accordingly. The fourth stage is the adjustment stage, in which the ability to adapt to the new cultural environment is gradually accepted and enjoyed and a sense of harmonious existence with the environment is generated. Lysgaard proposed the U-shaped curve theory of the three stages of cultural adaptation, and merged the last two stages of the four. Gullahorn proposed a five-stage W-curve theory of cultural adaptation, which added a mental isolation stage before the adaptation period. [4]

By summarizing the dynamic cross-cultural adaptation tracking cases of pre-university students, we find that the process of cultural adaptation of international pre-university students to China is quite different from the above theories. The cross-cultural adaptation of these students can be analyzed from two perspectives: one is group, and the other is individual.

\section{A. Cross-cultural Group Adaptation Process}

Most of the pre-university students' cultural adaptation stages features a relatively obvious five-stage adaptation process, namely excitement and harassment stage, anxiety stage, recovery stage, exhaustion stage and adaptation stage. The breakdown of the 10-month study of the pre-university students in China (from September of the first year to June of the second year) is as follows:

The first stage: excitement and harassment stage (the first to second weeks or the first two weeks of September). What pre-university students who first come to China shows is excitement and curiosity. However, their personal experience is not completely consistent with the information on China indirectly obtained in the past. Due to the existence of language barriers, it is impossible for them to conduct normal interpersonal communication with Chinese or other preuniversity students with different cultures. It is also difficult for them to adapt at one time to the unfamiliar learning environment and teaching methods,. So, they are psychologically in a dilemma and wonder what to do. This group needs to "go through a difficult process of overcoming cultural shocks, gradually shift from home culture to target culture in terms of language, life, communication and thinking.” [5] This process just gets started.

The second phase: anxiety period (the second to sixth weeks or the last two weeks of September to the first two weeks of October). At this stage, the pre-university students have more cultural incompatibility: They are no longer full of freshness for all things, hate to go to class and do not like to contact people except their fellow countrymen. They cannot accept the cold weather in autumn and winter and the physical diseases caused due to their poor adaptation to soil and water causes them trapped in even larger loss and anxiety.

The third stage: recovery period (the second to fourth months, November to January). In these three months, they have already stepped out of trough, basically understood the objective living and learning environment, and have small diseases on their bodies recovered. They can take the initiative to adapt to the life in China, and work hard to keep up with the teaching pace of Chinese teachers. Although they can't express their thoughts completely in Chinese, they have improved their listening and speaking skills a lot and have mastered some daily life expressions. The long-term contact with Chinese language partners has enabled them to conduct soul communication with their Chinese peers, and transnational friendship has smoothed their mental anxiety.

The fourth stage: exhaustion stage (the fifth to seventh months or December to March). This is a preparation period for the final exam of the first semester and for the HSK test in March. Long-term intensive training and a large number of simulated exams have made pre-university students exhausted. On the occasions of Christmas Day, New Year and Spring Festival, the pre-university students can't return to their homelands to visit relatives; the Chinese language partners have already gone home for winter vacation, and can no longer provide Chinese language tutoring and psychological counseling for these students. During this period, the preuniversity students can only make efforts in learning with their 
patience, which can be described as both physical and mental exhaustion.

The fifth stage: adaptation period (the eighth to tenth months or March to June, when all courses are completed). The second semester starts during the stage, and the pre-university students who have passed the test of HSK Level 4 feel extremely relaxed. The Chinese proficiency at the intermediate level allows them to communicate with the Chinese. The arrival of a new batch of Chinese language partners has expanded their social circles. Some Chinese specialized courses, such as mathematics, physics, business Chinese, are offered in this semester. These fresh specialized courses inject new vitality into the pre-university life. Under the long-term effective guidance of teachers, they have explored their own learning methods, become accustomed to the Chinese way of life, actively adjusted their mental state of learning, adapted to Chinese culture, and obtained a significant achievement in their academic performance. These students, who are going to complete all their courses, are reluctant to get separated from Chinese teachers and students as they have loved China. They have got integrated in Chinese culture and will pursue a two- to four-year undergraduate and postgraduate study.

According to the above analysis, the cross-cultural adaptation of pre-university students in China is divided into five stages and take on an N-shaped curve trend (see Fig. 1). The particularity of their group source and adaptation purpose determines that their cultural adaptation process cannot be interpreted by international well-formed cross-cultural adaptation theory. The application of international theoretical analysis to the pre-university students would lead to the intuition and simplification of the cross-cultural adaptation stage. It does not only lack scientific research proof, but also have the possibility of leading to errors and biases in teaching and management.

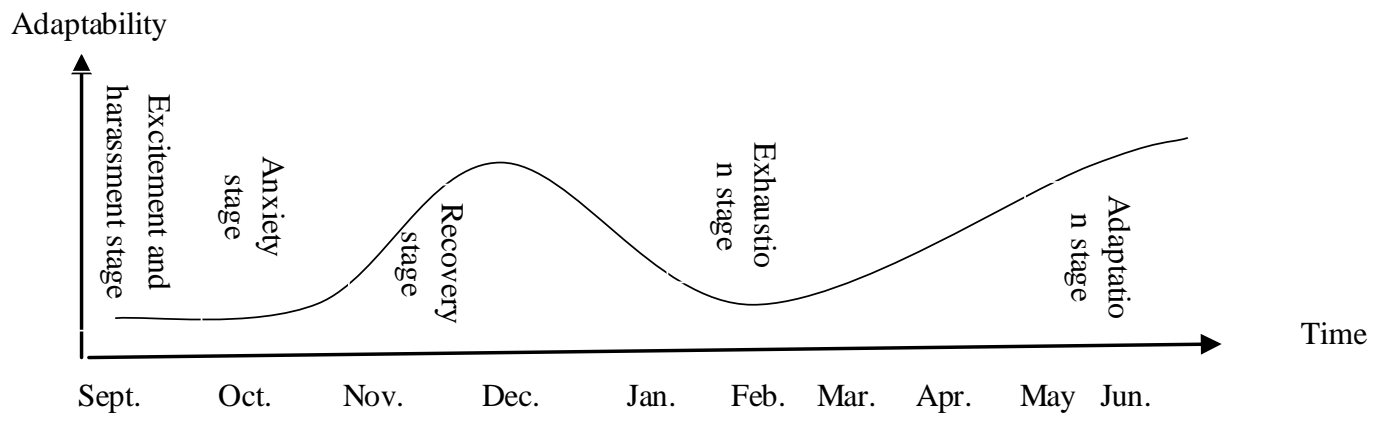

Fig. 1. N-type cross-cultural adaptation staging chart of pre-university students

\section{B. Reasons for Group Cultural Adaptation Issues}

According to the cases, the reasons for the adaptation issues of most pre-university students are quite common. The reasons can be divided into objective and subjective reasons. (See Table II) Objective reasons: (1) less adaptive to the living environment. In particular, pre-university students in Africa, Oceania and South America are unable to adapt to the cold and dry subtropical climate. Most pre-university students have had diseases such as colds and allergies. (2) less suitable to the learning environment, unable to cope with the fast-paced learning at the beginning. Subjective reasons: (1)With poor Chinese proficiency and language barriers, it seems difficult for them to communicate with pre-university students from other countries except China and Chinese people, with huge mental pressure. (2)Conflict of values. The behavioral styles of most pre-university students reflect the characteristics of individualistic values, and it is difficult for them to adapt to the collectivist values of China in the early stage. (3) The form of their communication differs from that of the Chinese, thus forming communication barriers. (4) Their family model and personality self-interpretation type are different from that of the Chinese. For example, the family model in Africa is mostly a dependent family model [6] 107 and cultural shock is caused by the dependence and thoughts of pre-university students on their relatives. (5) Lack of cross-cultural communication experience. Many students did not only come to China for the first time, but also went abroad for the first time, so they did not know much about cross-cultural communication conflicts.

TABLE II. REASONS FOR GROUP CULTURAL ADAPTATION ISSUES

\begin{tabular}{|l|l|}
\hline Objective reason & Subjective reason \\
\hline \multirow{2}{*}{ (1)Less adaptive to living environment } & (1)Poor language efficiency \\
\cline { 2 - 2 } & (2)Conflict of values \\
\hline \multirow{3}{*}{ (2) Less adaptive to learning environment } & (3)Cultural difference in communication forms \\
\cline { 2 - 2 } & (4)Difference in personality self-interpretation types \\
\cline { 2 - 2 } & (5) Lack of cross-cultural communication experience \\
\hline
\end{tabular}




\section{Individual Cultural Adaptation Process and Reasons}

The above-mentioned group cross-cultural adaptation staging does not apply to all pre-university students. There are a few pre-university students (about 15\% of the objects of study) who do not show anxiety or experience cultural shock. Their cross-cultural adaptation has shown a steady upward trend. These students are mainly pre-university students from East Asian cultural groups and Eastern Europe. The reasons are as follows: (1) They have a certain Chinese foundation and have studied Chinese before coming to China. (2) They have some understandings about China and they or their families and friends have been to China before. (3) They have some cross-cultural communication experience. For example, experiences of studying abroad or short-term stay in other countries. (4) They tend to have the independence-relationship self-interpretation personality [6] and are quite independent. For example, some Cambodian and Russian pre-university students have well-organized their life and study. They make friends with these Chinese, learn Chinese in communication, travel around China on festivals and holidays, and share their harvests with their families in time. The pre-university students with such tendency are mostly from the subjective world of collectivist culture. They live in cities, appear relatively independent in their actions, have a certain economic mind, and use scholarships scientifically. However, they still live in psychologically dependent families and have psychological dependence on their families. The prompt communication with their families constitutes the basis of their healthy psychology.

A small number of pre-university students have experienced a six-stage cultural adaptation process. After the anxiety period or about 4 months after coming to China, there is a long stage of loneliness. The reasons are described as follows: (1) They make a slow improvement and is reaching a plateau of language learning. (2)Students from middle-income families with financial difficulty have to face the severe employment pressure in the future, and will share the burden of their families in the future. (3) They show a tendency of sensitive and introverted personality and is unwilling to communicate with others. It can be seen that they have basically adapted to the objective Chinese social environment, and loneliness are mainly derived from their subjective psychological pressure. Some pre-university students from African civilian families have gone experienced this stage and closed themselves up. They were unwilling to participate in other activities of the pre-university education base in addition to learning. At this time, they were also unwilling to communicate with others. They would contact family members every day and even make a video chat with their families during Chinese language tutoring. With the help of teachers and language partners, they have finally got out of the loneliness stage. It should be pointed out that only one of the pre-university students concerned in all cases dropped out of school due to serious cultural shock.
IV. CROSS-CULTURAL ADAPTATION STRATEGIES AND COMMUNICATION FORMS OF PRE-UNIVERSITY STUDENTS

\section{A. Intercultural Adaptation Strategies}

According to the classification of cross-cultural psychology, pre-university students are sojourners or those who return to their hometown after staying abroad for a period of time. Therefore, they are unique in "maintaining the tradition and identity of their original culture and seeking the mode of establishing a new interpersonal relationship under the mainstream culture of the new environment" [7]. Therefore, the cultural adaptation strategies adopted by these students are different from other types of cross-cultural communication groups such as tourists, immigrants, and refugees.

In different stages of the cross-cultural adaptation process, the cultural adaptation strategies of the pre-university students would be adjusted as the adaptation changes. In the excitement and embarrassment stage and anxiety stages, they generally adopt a separation strategy to maintain their cultural identity and traditions. In the cases, the pre-university students were often together with their fellow countrymen. In addition to basic teaching activities, they would try to avoid contact or communicate with pre-university students from other countries or the Chinese. .

The result of case study discovers that the shifting of the pre-university cultural adaptation strategy was mostly changed with an event as an opportunity. These events have the common feature that pre-university students have achieved some success in this event, and they have used appropriate cross-cultural communication methods in solving specific problems, which has improved their intercultural communication skills and communication confidence. Most of the events were cultural events organized by the pre-university education base, such as the Chinese Reading Competition, the Chinese Singing Competition, and group travel. A typical event was recorded in a case of Chinese language partner": "One day, James (from Papua New Guinea) told me that he was sick using WeChat. So I bought him a box of capsules for treating the cold, handed over to one of his fellow countrymen and told the latter how to take the medicine in Chinese. The next day, I saw James, who was still a little weak but appeared much better in mental state. He was quite grateful to me for buying him medicine. After this matter, the relationship between James and me has become much closer. Recently, he learns Chinese more seriously. When he encounters any problem, he will consult me in time." The experience of seeing a doctor, shopping, and solving problems with the help of the Chinese has made the pre-university students' personal interactions with Chinese people more frequent. In summary, successful crosscultural communication experiences have enabled most preuniversity students to adopt an integration strategy. They have maintained their original culture and also accepted some values and behaviors in Chinese culture.

After half a year of cross-cultural adaptation, most preuniversity students have reached the end of the short-term cross-cultural adaptation process - the "sandwich culture layer". These students have formed "a sandwich culture with a variety of aggregates", which can "use the cultural characteristics of 
sandwiches to deal with different cultural characteristics” [3], thus laying a foundation for their long-term cultural adaptation in China for four years.

\section{B. Cross-cultural Communication Forms and Abilities}

When categorizing the cultural adaptation cases of individual events, we have identified two types of subject cases that are large in quantity, namely cases on non-verbal communication forms and abilities, and cases on language communication forms and abilities. Also, the theme of crosscultural communication runs through the vast majority of dynamic cross-cultural adaptation tracking cases and records in details the fact that cross-cultural communication forms for pre-university students accounted for $66 \%$ of all the cases.

\section{1) Nonverbal communication forms and abilities}

There are 87 non-verbal communication cases with the punctuality as theme. There are some cases on body language (26) and a few cases on facial language and personal space. Pre-university non-verbal communication forms with obvious cultural characteristics often lead to their communication barriers with Chinese.

Take punctuality as an example, most African and South American pre-university students would be late or absent, and would not follow the time schedule in the excitement and embarrassment stage and the anxiety stage. This seemed to be a violation of discipline and disrespect for teachers and classmates in the opinion of Chinese teachers, so this behavior was often criticized. More than $60 \%$ of Chinese students have appointed with African pre-university students for joint work, but the latter were finally late or missed the appointments. Most African students would not formally apologize afterwards Therefore, the Chinese Students would a negative impression on African pre-university students, thus affecting their future study and communication. This is because the traditional concept of time in Africa believes that time exists in events and is expressed through events. "They determine the reference point of computing time based on how an event or activity is important, so time is a quality not an abstract and accurate quantity in their minds. [8] Relatively speaking, Asian and European pre-university students have a strong sense of punctuality, and there would be no late or missed appointments among them, which leaves a good impression on the Chinese.

Body language cases show that the body language of African pre-university students is richer and more diversified than that of the counterparts from other countries, and there are more physical contacts. The non-verbal communication forms of African pre-university students, such as such as hugging, shouldering, veneering, and kissing are often discouraged by Chinese teachers and students who have been in contact with them. Even after a few months of contact, they still feel uncomfortable. African prep-university students think this is an unfriendly expression of the Chinese, which in turn creates a "inflexible" image of the Chinese. Some African students even loudly, "Why do Chinese people have no feelings!” Mehrabian once suggested, "In the face-to-face communication, among people's feelings, only $7 \%$ are derived from language while $38 \%$ from voice, and 55\% from facial expressions."[4]65 These figures show that nonverbal communication is the intercultural communication that are most likely to cause misunderstandings in cross-cultural communication. Therefore, it is necessary to increase the attention of pre-university students and Chinese teachers and students to non-verbal communication

\section{2) Language communication forms and abilities}

The language communication of international preuniversity students in China is quite complicated. They come from more than 40 countries and the official languages of these countries include English, French, Spanish, Portuguese, Vietnamese and others. Some students cannot speak English at all; and the students from some countries use several languages at the same time due to the special historical and cultural reasons, so what many pre-universities students are best at are the non-official language of their countries. All kinds of complicated language situations have brought great obstacles to Chinese teaching, management, and cross-cultural communication between teachers and students at the preuniversity education base.

Among $90 \%$ of the dynamic cross-cultural adaptation tracking cases, the communication barriers caused by language barriers during the excitement and embarrassment stage and anxiety stage are reflected, mostly in the following aspects: (1) Due to the reason of different countries, pre-university students have formed their communications circles based on country and they only communicate with those who speak in the same language with the former. (2) Due to the reason of official language, many pre-university students only communicate with students from other countries using the same language, thus forming a communication circle based on language. (3) It is difficult for the pre-university students who are Chinese beginners and who cannot speak English or are poor t at English to communicate with Chinese teachers and academic officers. Therefore, they often try to avoid communicating with the Chinese, which makes these students show the symptom of cultural shock and enter into the anxiety stage during the cultural adaptation.

With the improvement of Chinese proficiency and slight easing of communication barriers, new problems arise. More than $26 \%$ of the cases reflect cross-cultural communication barriers caused by cultural background of language and language communication style.

'The communication style in any communication features high context, low context or a middle context." [9] The high context interaction is characterized by the storage of information stored in the recipient and its background. For low context interaction, most of the information must be included in the message delivered to compensate for the missing information in the context. Communication style is correlated with values; individualistic culture tends to show a low-context communication style, clear and direct; and collectivist culture tends to exhibit a high-context communication style, euphemistic and indirect.

Chinese culture embodies the characteristics of collectivist culture, and the high context euphemistic communication style is its obvious manifestation. High context requires both parties to have a shared background and raise higher requirements for 
language proficiency. Often, pre-university students and the Chinese often cannot accurately understand the meaning what a Chinese say when talking with the Chinese due to his/her lack of Chinese cultural background and limitation of Chinese proficiency. Many communications are only confined to literal meanings and the means beyond the words cannot be understood. While considering both parties' feelings, the Chinese habitually use the high-context communication style in the expressions of language functions such as negotiation, rejection, and invitation. Thus, in the mid-to-late period, there would often misunderstandings between pre-university students and the Chinese in their in-depth interaction. Therefore, pre-university students should not only improve their Chinese proficiency but also learn the communication styles with Chinese characteristics. The educational content of communication forms and abilities should also be included in the pre-university international talent development plan.

\section{IMPLICATIONS OF CROSS-CULTURAL ADAPTATION STUDY FOR THE CULTIVATION OF INTERNATIONAL TALENTS IN PRE-UNIVERSITY EDUCATION}

There are three goals for the education of pre-education students in China: 1 . enable pre-university students to pass the HSK test and CSC exam through one to two years of preuniversity training program. 2. Improve the Chinese proficiency of pre-university students, and help them smoothly enter into Chinese universities to learn Chinese in a professional way. 3. Improve the cross-cultural communication skills of pre-university students and get them prepared for the long-term cultural adaptation to their undergraduate studies in China. The first goal is a short-term goal, and the other two are long-term ones. Therefore, the preparatory education must take the overall situation into account, consider both long- and short-term goals, and pursue the overall design that reflects the characteristics of international talent training. The reflection and suggestions on the existing pre-university training model are described as follows:

\section{A. Advantages and Disadvantages of Accelerated Chinese Teaching Model}

In order to enable the pre-university students to pass the assessment and achieve short-term goals, all pre-university education bases in the country have adopted the accelerated Chinese teaching model. This model has both advantages and disadvantages.

The case study shows that in the early days of arriving in China, pre-university students learnt a large amount of Chinese knowledge in a completely unfamiliar language system, especially pinyin and Chinese words. Due to the different language pedigrees, the combination of Chinese pronunciations, word forms and meanings is a major difficulty for preuniversity students. $90 \%$ of the pre-university students thought that Chinese words are the most difficult part of the four elements of the language (speech, vocabulary, grammar and Chinese words). It is quite difficult for them to learn Chinese. If the Chinese language acquisition method used by the preuniversity students is not suitable, the learning effect would be affected in a short term, and psychological anxiety will arise. The intense learning atmosphere of the model is quite different from the teaching atmosphere of most pre-university students, and it is difficult for them to adapt it at one time. Therefore, the pre-university students can't help but comparing the educational models, and they have negative emotions due to both physical and psychological discomfort, and even have some cultural shock response.

On the other hand, the accelerated Chinese teaching model would promote the cultural adaptation of the pre-university students. It can enable the language proficiency of the preuniversity students to obtain a great improvement in a short term so that the communication with the Chinese will become smoother, and the pre-university students' confidence will be increased. As a result, their symptom of cultural shock will be eased and get disappeared.

The key point of bringing to the positive role of the teaching mode is to take into account the long-term and shortterm teaching objectives, start from the overall teaching design, textbook selection, classroom teaching and test evaluation, and carry out reverse design. Make the learned knowledge and skills be used in the real cross-cultural communication situations, and effectively combine examination and communication skills.

\section{B. Using both Classroom and Extracurricular Teaching to Enhance Cross-cultural Adaptability}

\section{1) Classroom teaching}

Classroom teaching is the main part of pre-university Chinese teaching, and we should try our best to create a Chinese classroom that gets close to the real cross-cultural communication environment. In the post-method era of Chinese teaching, various teaching methods are organically combined. The case study shows that pre-university students will have cultural conflicts with the Chinese because of different communication methods between them. Therefore, the proportion of communication teaching method and body culture teaching method should be increased in the classroom.

The communication-based teaching method is famous for teachers' cross-cultural questioning skills, and is good at creating a communication context with cross-cultural communication as feature. Make explains, make exercises, and conduct thematic activities within the context. Therefore, it is possible to train pre-university students to form a high-context communication style with Chinese culture as background and improve their communication skills with the Chinese. The body culture teaching method emphasizes behavioral culture teaching, and encourages the simulation of real communication situation in the classroom. Students should fully internalize their language knowledge and skills, and carry out meaningful and interesting language exercises and theme activities in the dramatic situational performance form. [10] These two methods of teaching can be combined with the case teaching method. For example, when performing functional exercises such as invitation, suggestion, and refusal, you can use real cross-cultural communication cases as a corpus for teaching. The dialogue between pre-university students and their Chinese teachers and language partners is restored, and the roles are played in the classroom. The cultural functions behind the language are compared and analyzed, and the dialogue model 
with the best communicative effect is obtained. It can achieve a multi-dimensional application of the cases, not only in scientific research, but also in classroom teaching.

Therefore, in the classroom, teachers should minimize the teaching and explanation of the language structure, add master interaction among teachers and students and interactions among students, and incorporate more functional exercises and activities that reflect the characteristics of cross-cultural communication. The classroom teaching that is applied into practice will definitely improve the learning interest of preuniversity students, strengthen their motivation of learning, and form a virtuous circle of teaching and learning.

\section{2) Extracurricular teaching}

The case study shows that most of the pre-university students will pursue long-term independent study outside the extracurricular time beyond teacher monitoring. However, the self-study that lacks effective guidance often causes the misunderstanding of meaningless mechanical exercises, and even causes physical and mental fatigue and then cultural shock. Therefore, the full and effective use of spare time and the planning of extracurricular teaching are the special features of pre-university Chinese teaching. This requires teachers of all disciplines to work together and use the task-based approach to organically combine classroom and extracurricular teaching. They should develop detailed extracurricular task-based activities and use extracurricular activities as an extension of classroom instructions; incorporate various extracurricular activities such as visit, tourism, competition, evening party, etc. into teaching, and combine flexible personal activities with well-arranged collective activities. They should make extracurricular activities the opportunity and turning point for pre-university students to adapt to cultural adaptation strategies and better integrate into Chinese society.

3) The role of Chinese and international students in crosscultural interaction

The use of Chinese college students as language partners for international students has long been adopted in various forms of education abroad. In the pre-university training, it is necessary to go deeper into the role of language partner. From the recruitment of language partners, the cross-cultural communication training of language partners, participation in the extracurricular activities of the pre-university students to the communication with the teachers, benign feedback channel should be formed and a set of system featuring scientific education support by language partner should be built.

The case study demonstrates that cross-cultural adaptation is a two-way process, and requires the cooperation and assistance of Chinese students as it can accelerate the crosscultural adaptation of international students. For pre-university students and Chinese college students, "the identity of the respective groups they represent may be reclassified on the multicultural campus of Chinese universities, which can increase integration and reduce the prejudice and conflict among original classified groups.” [3] 236 In short, The Preuniversity Education Base for international students in China provides a quality adaptation environment for the preuniversity students from the rest of the world. In this environment, although the cross-cultural adaptation of preuniversity students is diverse, complex, and changing, there are still rules to follow. We should fully understand the process of interdisciplinary students' cross-cultural adaptability and thinking, from opposition to collision to promotion, and develop the international pre-university education from the field of language education to the new field of cultural communication education, improve the Chinese teaching model of examination-oriented intensive training, and train the international talents of next generation with greater crosscultural communication vision and ability.

\section{REFERENCES}

[1] CAO Jianing. The Main Sources of International students are the Countries along the Belt and Road, Talent Training Features Wide Fields and Multiple Layers. (In Chinese).

https://www.yidaiyilu.gov.cn/xwzx/gnxw/37638.htm.

[2] CHEN Xiangming. Qualitative Research and Social Sciences [M]. Beijing: Education Science Press. 2000. (In Chinese).

[3] AN Ran. Cross-cultural Communication and Adaptation Research [M]. Beijing: China Social Sciences Press. 2011. (In Chinese).

[4] YAN Wenhua. Cross-cultural Communication Psychology [M]. Shanghai: Shanghai Academy of Social Sciences Press. 2008. (In Chinese).

[5] BI Jiwan. Cross-cultural Communication and Second Language Teaching [M]. Beijing: Beijing Language and Culture University Press. 2009:430. (In Chinese).

[6] [UK] Smith, [Canada] Penmike, [Turkey] Kucha Basha. Cross-cultural Social Psychology [M]. Translated by YAN Wenhua, QUAN Dayong, etc., Beijing: People's Posts and Telecommunications Press. 2009. (In Chinese).

[7] ZU Xiaomei. Cross-cultural Communication [M]. Beijing: Foreign Language Teaching and Research Press. 2015: 146. (In Chinese).

[8] ZHANG Hongming. African Traditional Time Concept [J]. West Asia and Africa, 2004 (6): 40. (In Chinese).

[9] [USA] Edward Hall. Transcending Culture [M]. He Daokuan, Beijing: Peking University Press. 2010: 101. (In Chinese).

[10] [USA] Chief Editor Wu Weike. Body Culture Teaching Method [M]. Wuhan: Hubei Education Press. 2010. (In Chinese). 